\title{
Hydraulic Operation of the Spillway for the Lom Pangar Dam in Cameroon
}

\author{
Biya Motto Frederic ${ }^{1}$, Tchuidjan Roger ${ }^{2}$, Ndzana Benoit ${ }^{2}$, \\ Asonganyi D. N. Austin ${ }^{3}$. \\ ${ }^{I}$ Faculty of Science, University of Yaoundé I \\ ${ }^{2}$ National School of Engineering Yaoundé, \\ ${ }^{3}$ Mekin Hydroelectric Development Corporation, PO Box 13155, Yaounde
}

\begin{abstract}
This paper lists the restitution capacity of the spillway at different times and then shows by calculation that it is functioning properly. The Numerical modelling of the spillway was carried out using the HEC-RAS software of the US Army Corps of Engineers (USACE) and is limited to a single passage of $8.75 \mathrm{~m}$ wide. The aim of the calculation is to obtain the flow conditions at the entrance of the restitution bucket where the water flow is at supercritical depth.
\end{abstract}

Keywords: Spillway, flood dissipation, cavitation, bucket, ski jump, Lom Pangar.

\section{Introduction}

Lom Pangar is a dam in the Eastern Region of Cameroon and its water is used in the regulation of the downstream water level during the dry season for the Sanaga river. For the evacuation of flood, it is equipped with a surface spillway (Creager classic type) designed for a deca-millennial flood. It consists of:

- 4 Passages $8.75 \mathrm{~m}$ wide, each equipped with a segment valve of which the height is fixed at altitude 665.75

CGL (Cameroon geodesic level).

- 3 flood discharge gates $(2 \times 5.9 \mathrm{~m} \times 4 \mathrm{~m})$ and $(1 \times 3 \mathrm{~m} \times 2 \mathrm{~m})$ at CGL 640 and 643 respectively.

- A free overflow passage of $11 \mathrm{~m}$ wide on the right bank at altitude 672.70 CGL fitted with a Hydroplus fuse.

- For the hydroplus fuse to tilt, the water level must attain 674.55 CGL at which time the freeboard will be a little above $3 \mathrm{~m}$ as the crest of dam is at $677.55 \mathrm{CGL}$

The hydraulic regime on the threshold passage is determined by the flow control section situated at the level of the pier: at this point the draft height is equal to the calculated critical height of the evacuated flow.

\section{Evacuation Capacity}

The evacuation capacity of the spillway at full overture for the different feasible configurations are shown in the figure 1

At normal reservoir retention the discharge capacity of each gated passage is $320 \mathrm{~m}^{3} / \mathrm{s}$.

At normal conditions of exploitation (4 gated passage) the discharge capacity is $1280 \mathrm{~m}^{3} / \mathrm{s}$ plus 3 flood discharge gates with a total capacity of $860 \mathrm{~m}^{3} / \mathrm{s}$ making a total of $2140 \mathrm{~m}^{3} / \mathrm{s}$.

\section{Analysis Of The Different Flood Situations}

A lamination of the different flood returns for 100, 1000 and10,000 years has been studied for the following configurations:

- Normal conditions: all the hydromechanics equipment are operational

- Special conditions: one of the passageway gates is supposedly blocked

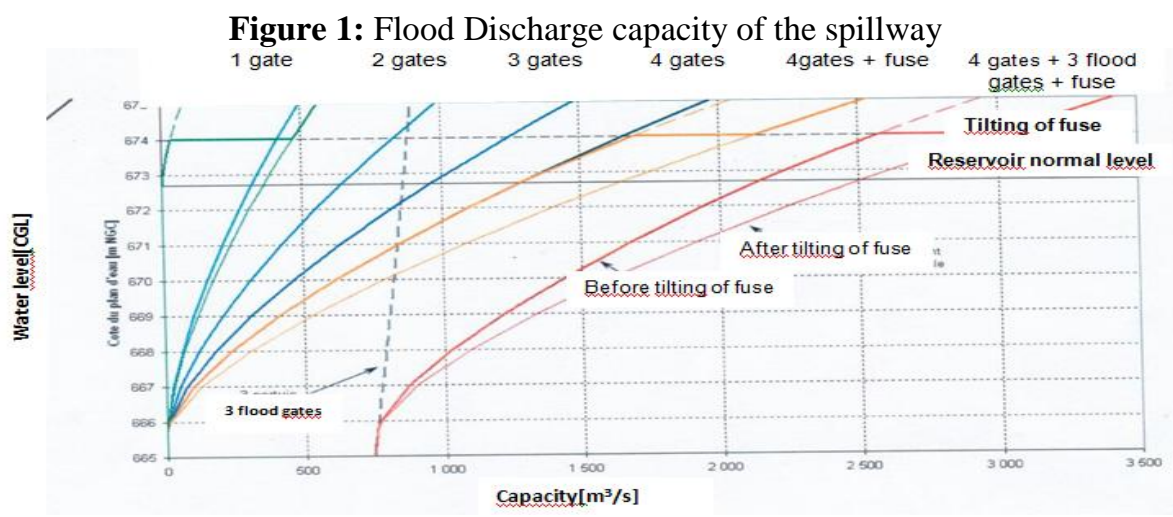




\section{Flood Hydrographs}

A hydrograph for the different flood used (From studies and simulations carried out in pre-project doc No. 10108-NDC-0100)

Figure 2: Hydrograph of flood (T=100, 1000, 10,000, and PMF)

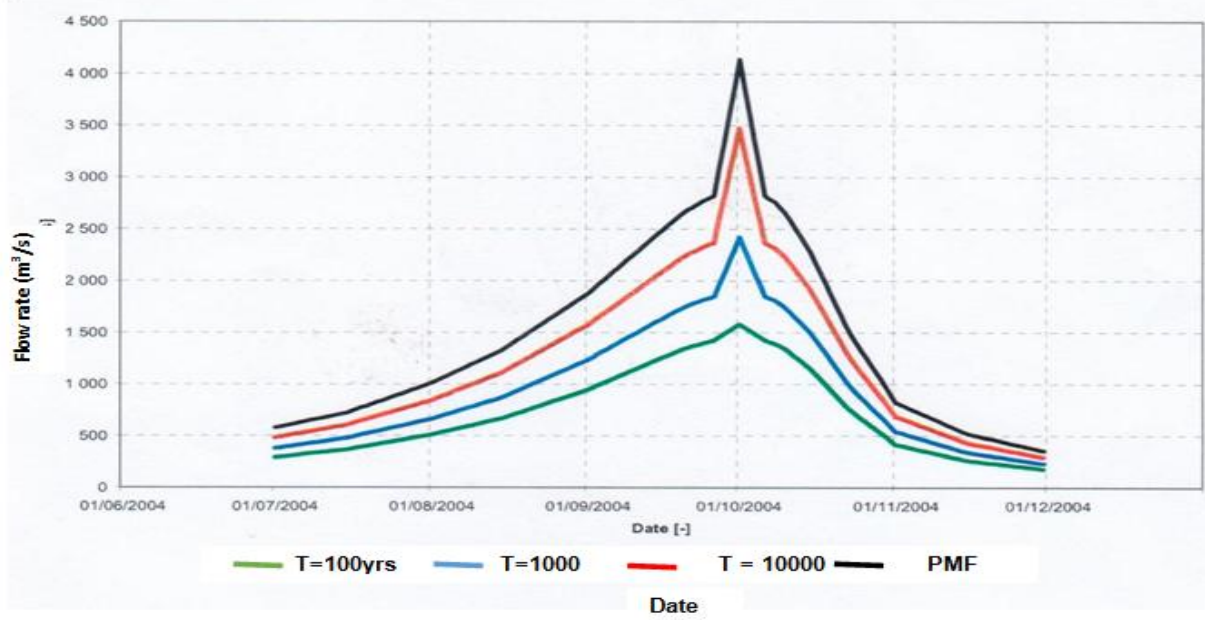

The flood dissipation capacity was then analysed for normal conditions (4 segment gates operational) and special conditions ( 3 segment gates operational) as shown below

Figure 3: Analysis of the PMF - Normal conditions (4 gates + 3 flood discharge gates + supplementary outlet)

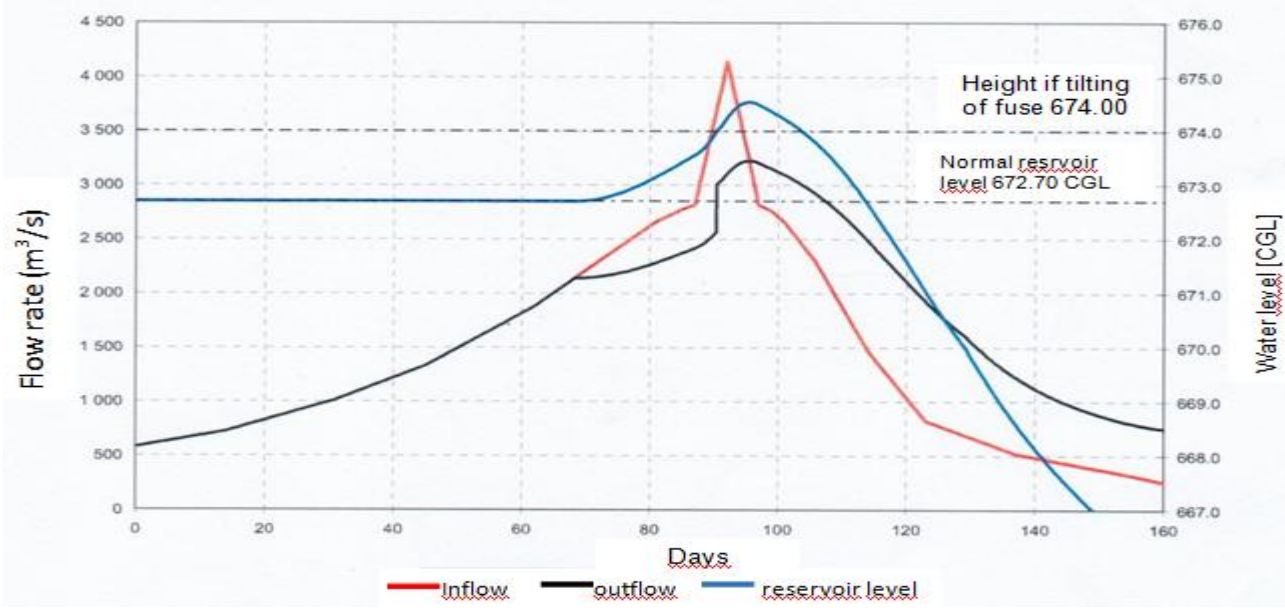

Figure 4: Analysis of the PMF - Exceptional conditions

(3 gates + 3 flood discharge gates + supplementary outlet)

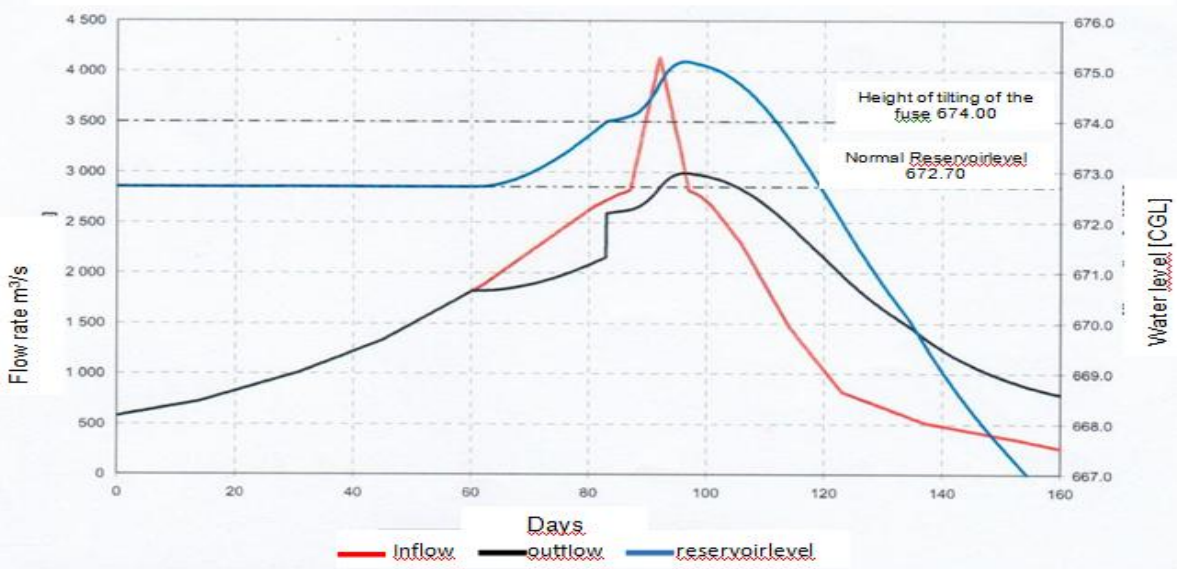


Figure 5: Maximum water level with respect to the return flood

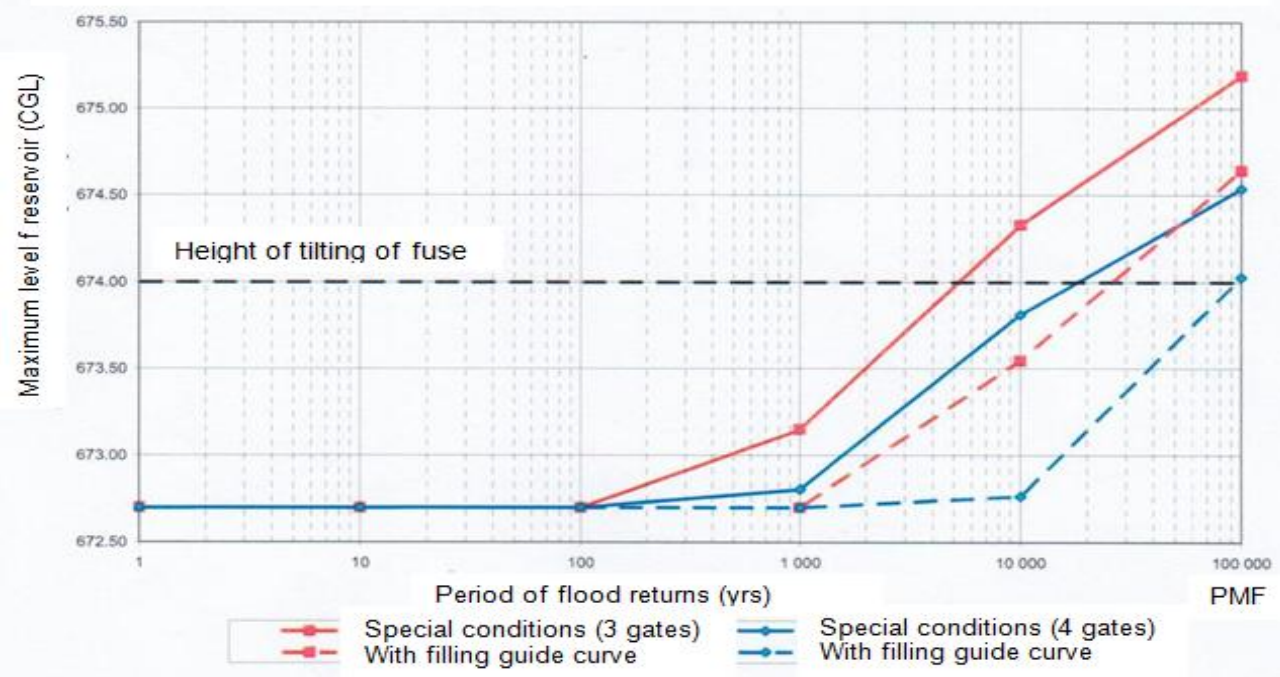

Water level during 1/10000 year flood returns reach the height of 674.33 and if one of the gates is nonoperational, this could cause a tilting of the fuse, a very rare condition.

\subsection{Numerical modelling}

\section{Hydraulic Functioning Of The Spillway[3]}

The principal hypotheses used in this modelling are as follows: (i) the surface of the water line is modelled in steady state for laminated flow (ii) the Strickler coefficient (of concrete) in the passageway of the spillway is considered being equal to 70 (iii) The entrance of the bucket is fixed at altitude 647.50 CGL.

\subsection{Analytical method}

In applying the Bernoulli equation, the results obtained are identical to some degree, to the section situated between upstream of spillway $(\mathrm{Z}=672.70 \mathrm{CGL}, \mathrm{V}=0)$ and the bucket taking into account the coefficient of load loss is equal to 0.9 .

\section{Defining the cavitation index}

\section{Studying The Risk Of Cavitation}

The cavitation index $\sigma_{1}$ is non-dimensional value defined classically in free surface flow as follows:

$$
\sigma_{1}=\frac{P_{a t m}+h-P_{v a p s a t}}{\frac{v^{2}}{2 g}}
$$

Where:

$\begin{array}{ll}\mathrm{P}_{\text {atm }} & \text { atmospheric pressure } \mathrm{mH}_{2} \mathrm{O}, \\ \mathrm{H} & \text { height of water flow in } \mathrm{mH}_{2} \mathrm{O}, \\ \mathrm{P}_{\text {vap sat }} & \text { vapour saturation pressure in } \mathrm{mH}_{2} \mathrm{O}, \\ \mathrm{v} & \text { average speed in } \mathrm{m} / \mathrm{s}, \\ \mathrm{g} & \text { acceleration due to gravity }\end{array}$

The recommendations by US Bureau of Reclamation concerning the cavitation index are as follows:

- For all projects in which $\sigma_{1}<0.1$ must be reconsidered

- Projects having $0.1<\sigma_{1}<0.2$ need measures of aeration to limit cavitation risks

- Projects in which $\sigma_{1}>0.2$ may not need aeration on condition that the concrete finishing is in adequacy with the value of $\sigma_{1}$.

\section{Study Of Cavitation Index Along The Spillway}

The water height and speed are determined along the spillway for millennial and deca-millennial flood from hydraulic simulations realized with the HEC-RAS software. The sections used for calculations of the cavitation index correspond to the construction sections defined in the software. The sections used for the calculation correspond to a block from the entrance to the spillway to the entrance to the bucket. 
Table 1: Study of cavitation risk from upstream to downstream

\begin{tabular}{|c|c|c|c|c|c|}
\hline Sections considered & Return period & $\mathbf{V}$ & $\mathbf{h}$ & $\sigma_{\mathrm{i}}$ & Cavitation \\
\hline & [Years] & {$[\mathrm{m} / \mathrm{s}]$} & {$\left[\mathrm{mH}_{2} \mathrm{O}\right]$} & {$[-]$} & {$[-]$} \\
\hline 7 & $\begin{array}{c}\mathrm{T}=1000 \mathrm{yrs} \\
\mathrm{T}=10000 \mathrm{yrs}\end{array}$ & $\begin{array}{l}7.20 \\
7.53\end{array}$ & $\begin{array}{l}5.10 \\
4.87\end{array}$ & $\begin{array}{l}5.71 \\
5.14\end{array}$ & $\begin{array}{l}\sigma_{i}>0.2 \\
\sigma_{i}>0.2\end{array}$ \\
\hline 6 & $\begin{array}{c}\mathrm{T}=1000 \mathrm{yrs} \\
\mathrm{T}=10000 \mathrm{yrs}\end{array}$ & $\begin{array}{l}8.39 \\
8.73\end{array}$ & $\begin{array}{l}4.37 \\
4.20 \\
\end{array}$ & $\begin{array}{l}4.00 \\
3.65\end{array}$ & $\begin{array}{l}\sigma_{i}>0.2 \\
\sigma_{i}>0.2\end{array}$ \\
\hline 5 & $\begin{aligned} \mathrm{T} & =1000 \mathrm{yrs} \\
\mathrm{T} & =10000 \mathrm{yrs}\end{aligned}$ & $\begin{array}{c}9.79 \\
10.13\end{array}$ & $\begin{array}{l}3.75 \\
3.62\end{array}$ & $\begin{array}{l}2.81 \\
2.61\end{array}$ & $\begin{array}{l}\sigma_{i}>0.2 \\
\sigma_{i}>0.2\end{array}$ \\
\hline 4 & $\begin{aligned} \mathrm{T} & =1000 \mathrm{yrs} \\
\mathrm{T} & =10000 \mathrm{yrs}\end{aligned}$ & $\begin{array}{l}11.17 \\
11.49\end{array}$ & $\begin{array}{l}3.28 \\
3.19\end{array}$ & $\begin{array}{l}2.08 \\
1.96\end{array}$ & $\begin{array}{l}\sigma_{i}>0.2 \\
\sigma_{i}>0.2\end{array}$ \\
\hline 3 & $\begin{array}{c}\mathrm{T}=1000 \mathrm{yrs} \\
\mathrm{T}=10000 \mathrm{yrs}\end{array}$ & $\begin{array}{l}12.56 \\
12.87\end{array}$ & $\begin{array}{l}2.92 \\
2.85\end{array}$ & $\begin{array}{l}1.61 \\
1.53\end{array}$ & $\begin{array}{l}\sigma_{i}>0.2 \\
\sigma_{i}>0.2\end{array}$ \\
\hline 2 & $\begin{array}{c}\mathrm{T}=1000 \mathrm{yrs} \\
\mathrm{T}=10000 \mathrm{yrs}\end{array}$ & $\begin{array}{l}13.96 \\
14.27 \\
\end{array}$ & $\begin{array}{l}2.63 \\
2.57\end{array}$ & $\begin{array}{l}1.27 \\
1.22 \\
\end{array}$ & $\begin{array}{l}\sigma_{i}>0.2 \\
\sigma_{i}>0.2\end{array}$ \\
\hline 1 & $\begin{aligned} \mathrm{T} & =1000 \mathrm{yrs} \\
\mathrm{T} & =10000 \mathrm{yrs}\end{aligned}$ & $\begin{array}{l}16.05 \\
16.34\end{array}$ & $\begin{array}{l}2.29 \\
2.25\end{array}$ & $\begin{array}{l}0.94 \\
0.90\end{array}$ & $\begin{array}{l}\sigma_{i}>0.2 \\
\sigma_{i}>0.2\end{array}$ \\
\hline 0 & $\begin{array}{c}\mathrm{T}=1000 \mathrm{yrs} \\
\mathrm{T}=10000 \mathrm{yrs}\end{array}$ & $\begin{array}{l}20.79 \\
21.05 \\
\end{array}$ & $\begin{array}{l}1.76 \\
1.74 \\
\end{array}$ & $\begin{array}{l}0.53 \\
0.53 \\
\end{array}$ & $\begin{array}{l}\sigma_{i}>0.2 \\
\sigma_{i}>0.2\end{array}$ \\
\hline-1 & $\begin{array}{c}\mathrm{T}=1000 \mathrm{yrs} \\
\mathrm{T}=10000 \mathrm{yrs}\end{array}$ & $\begin{array}{l}21.48 \\
21.75 \\
\end{array}$ & $\begin{array}{l}1.71 \\
1.69 \\
\end{array}$ & $\begin{array}{l}0.49 \\
0.49 \\
\end{array}$ & $\begin{array}{l}\sigma_{i}>0.2 \\
\sigma_{i}>0.2\end{array}$ \\
\hline-2 & $\begin{array}{l}\mathrm{T}=1000 \mathrm{yrs} \\
\mathrm{T}=10000 \mathrm{yrs}\end{array}$ & $\begin{array}{l}21.66 \\
21.93\end{array}$ & $\begin{array}{l}1.69 \\
1.67\end{array}$ & $\begin{array}{l}0.49 \\
0.47\end{array}$ & $\begin{array}{l}\sigma_{i}>0.2 \\
\sigma_{i}>0.2\end{array}$ \\
\hline-3 & $\begin{array}{c}\mathrm{T}=1000 \mathrm{yrs} \\
\mathrm{T}=10000 \mathrm{yrs}\end{array}$ & $\begin{array}{l}21.72 \\
21.99 \\
\end{array}$ & $\begin{array}{l}1.69 \\
1.67 \\
\end{array}$ & $\begin{array}{l}0.49 \\
0.47 \\
\end{array}$ & $\begin{array}{l}\sigma_{i}>0.2 \\
\sigma_{i}>0.2\end{array}$ \\
\hline
\end{tabular}

The conditions of non-cavitation are verified in each of the sections of the spillway. It is consequently not necessary to envisage the setup of an aerator.

\section{Analysis Of The Downstream Restitution}

In this section, the main results presented are applicable to the evacuation bucket defined by horizontal cylinder of radius $12 \mathrm{~m}$ of which the angle of exit of water from the jet is equal to $31^{0}$.

\subsection{Recall on the hydraulics of ski jump[2][5[7][8][9]}

This type of analysis carries the following conclusions

- The repartition of dynamic pressure at the bucket,

- The conditions of forming a hydraulic jump at the bucket,

- The characteristics of the trajectory of the jet water coming out of the bucket,

- The height of waves at the downstream of flow regulatory structures

The sketch of figure 6 represents the flow in coming out of the bucket of a ski jump and is the set of notations used hereafter.

\section{Figure 6: Flow pattern in coming out of the bucket in ski jump: notations} are used hereafter

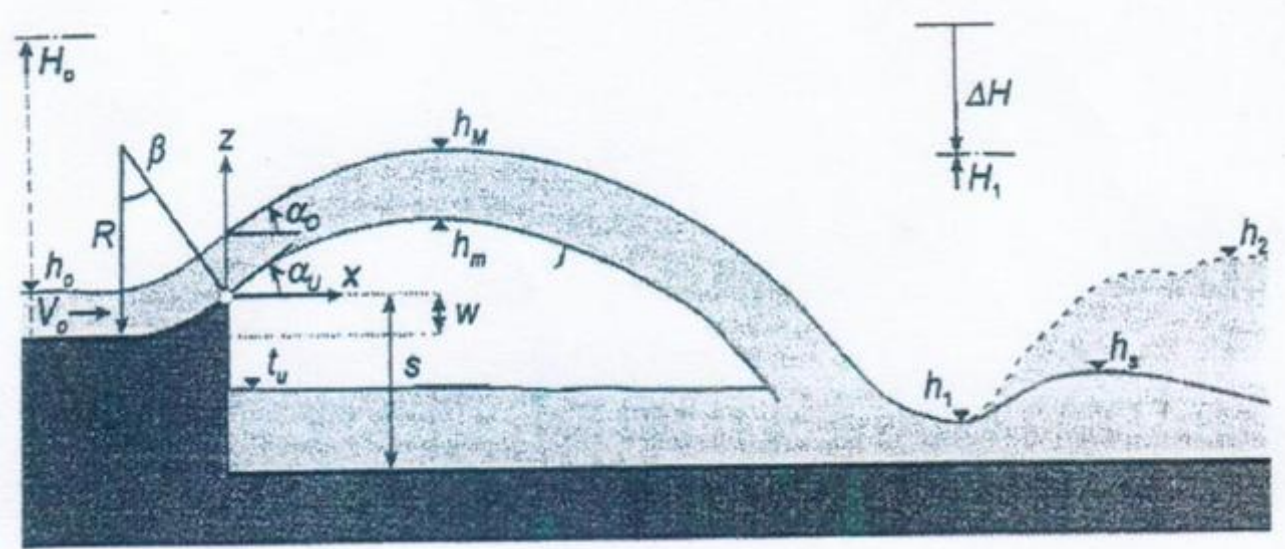




\subsection{Maximum dynamic pressure along the bucket}

The theoretical dynamic pressure $\mathrm{H}_{\mathrm{PT}}$ exerted by a flow rate $\mathrm{Q}$ on a bucket of radius of curvature $\mathrm{R}$ is calculated as follows:

$$
\frac{H_{P T}}{h_{0}}=B_{0}^{2}[4]
$$

With $B_{0}=\sqrt{\frac{h_{0}}{R}} \times F_{0}$ where $B_{0}$ is the number curvature

Experience has shown that the maximum pressure observed, noted $\mathrm{H}_{\mathrm{PM}}$ is deduced from the Term $\mathrm{H}_{\mathrm{PT}}$ as follows:

$$
\left.\frac{H_{P M}}{H_{P T}}=\frac{R}{5 \cdot h_{0}} \times \frac{\beta}{40^{0}} \text { (on condition that } \frac{R}{h_{0}} \times \frac{\beta}{40^{0}} \geq 0.20\right)
$$

The position $\mathrm{X}_{\mathrm{PM}}$, completed negatively since the coming out from the bucket to the point of maximum dynamic pressure for an angle of curvature greater than $15^{\circ}$ is given by the relation below:

$$
\frac{X_{P M}}{R \cdot \sin \beta}=-\left(\frac{1.5^{0}}{\beta}\right)^{1.5}
$$

\subsection{Characteristic of the trajectory of the jet on coming out of the bucket[4]}

If we neglect the friction of air on water, the layers of water inferior or superior to the water jet describe, on coming out of the bucket, a parabola which can be represented using the ballistic equation:

$$
\mathrm{z}(\mathrm{x})=z_{0}+\mathrm{x} \cdot \tan \left(\alpha_{j}\right)-\frac{g x^{2}}{2 \cdot V_{0}^{2} \cdot \cos ^{2}\left(\alpha_{j}\right)}
$$

where

x horizontal distance

$\mathrm{z} \quad$ height

$\mathrm{z}_{\mathrm{o}} \quad$ height of point of departure of jet

$\mathrm{V}_{0} \quad$ flow speed at the entrance of bucket

$\alpha_{\mathrm{j}} \quad$ angle of water blades with respect to the horizontal, on coming out of the bucket

In order to take into account the non-negligible effects of friction due to air at this speed, the velocity at upstream of bucket $\mathrm{V}_{0}$ is corrected by coefficient taken equal to 0.85 . The angle of water of the lower layer, denoted as $\alpha_{U}$, as well as that of the upper layer denoted as $\alpha_{\mathrm{o}}$ are given by the following equations:

$$
\begin{aligned}
& \frac{\alpha_{o}}{\beta} \mathrm{X}\left(\frac{70^{o}}{\beta}\right)^{1 / 6}=\frac{1}{2}\left[1+\exp \left(-8\left(h_{o} / R\right)^{2}\right)\right] \text { for } 0 \leq \mathrm{h}_{\mathrm{o}} / \mathrm{R} \leq 1 \\
& \frac{\alpha_{U}}{\beta} \mathrm{X}\left(\frac{140^{o}}{\beta}\right)^{1 / 6}=\frac{1}{2}\left[1+\exp \left(-8\left(h_{o} / R\right)^{2}\right)\right] \text { for } 0 \leq \mathrm{h}_{\mathrm{o}} / \mathrm{R} \leq 1
\end{aligned}
$$

Where $h_{o}$ is the height of water at the entrance of bucket

\subsection{Height of waves downstream and at zones of recirculation}

At the zone of impact, the flow generates turbulence and shockwaves. Observations from reduced models have permitted us obtain a relation (8) linking the height of the wave downstream to the Froude number at the entrance of the bucket and the angle of deflection of the bucket. Similarly, the expression (9)permits us to determine the height of the recirculation zone to the jet situated between the point of impact of the jet and the downstream facing of the structure.

$$
\begin{array}{ll}
\left(\frac{h_{S}}{h_{o}}-1\right) \sqrt{\sin \beta}=0.85\left(F_{o}-1\right) & \text { for } 2 \leq\left(\mathrm{F}_{\mathrm{o}}-1\right) \leq 10 \\
\frac{t_{u}}{h_{o}}=\left(5 F_{o}^{-1}\right)^{2} & \text { for } 3 \leq \mathrm{F}_{\mathrm{o}} \leq 10
\end{array}
$$

\subsection{Condition for the formation of a hydraulic jump in the bucket}

Classically, each ski jump is designed so that the flow remains in torrential flow in the bucket so as to propel water as far as possible thus avoiding erosion at the foot of the downstream facing. In case where the flow at the entrance of the bucket does not have a large Froude number, a hydraulic jump can occur and inundate the bucket. The jet does not take off and the water is disbursed at the extreme of downstream of the bucket. Two types of flow are possible:

- Case 1: Flow increase regime

- Case 2: Flow decrease regime 
Figure 7: Condition of forming a hydraulic jump in the bucket

\section{Case 1: Increased flow rate}

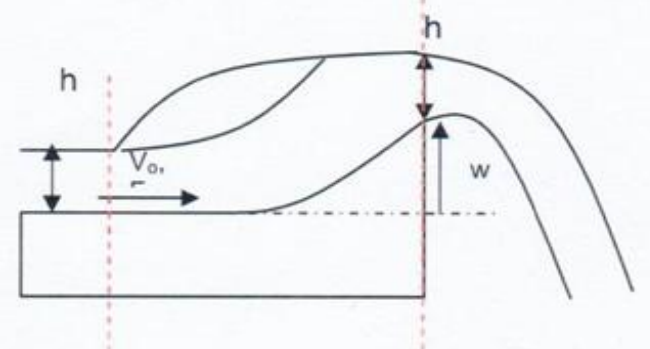

\section{Upstream} section

\section{Downstrea \\ m section}

\section{Case 2: Decreased flow rate}

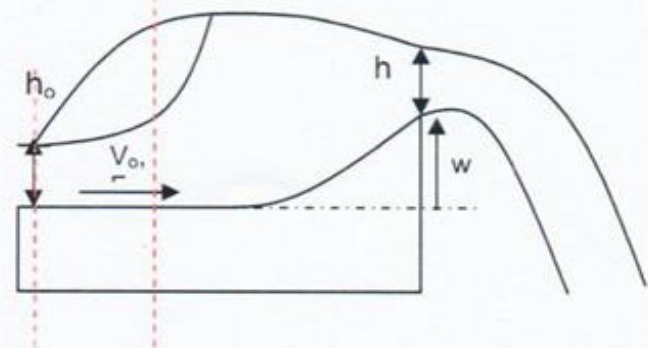

Upstream Downstrea

m section

The application of Euler's theory to the volume comprised between the upstream and downstream sections in a hypothesis of forming a hydraulic jump leads us to the following results:

Case 1: $\mathrm{W}^{+}=\frac{W}{h_{o}}=0.6\left(\mathrm{~F}_{\mathrm{o}}-1\right)^{1.2} \quad 1<\mathrm{F}_{\mathrm{o}}<4$

Case 2: $\mathrm{W}^{+}=\frac{W}{h_{o}}=0.9\left(\mathrm{~F}_{\mathrm{o}}-1\right)^{0.9} \quad 1<\mathrm{F}_{\mathrm{o}}<4$

For a given geometry and characterised by its $\mathrm{W} / \mathrm{h}_{\mathrm{o}}$ ratio, we are capable of determining the flow rate at which a jump is formed in the bucket. For flows superior to this value, the flow remains torrential.

\section{Evaluating The Risk For A Hydraulic Jump In The Bucket}

The following table synthesizes the results obtained. The conditions of formation of a hydraulic jump is never verified except for a flow of $10 \mathrm{~m}^{3} / \mathrm{s}$.

Table 2: Evaluation of the formation of a hydraulic jump in a bucket

\begin{tabular}{|l|l|l|l|l|l|l|}
\hline Flowrate per passage & $\mathbf{h}_{\mathbf{o}}$ & $\mathbf{F}_{\mathbf{o}}$ & $\mathbf{W}$ & \multicolumn{1}{|c|}{$\boldsymbol{F}_{o}^{+}$} & \multicolumn{1}{c|}{$\boldsymbol{F}_{\mathbf{o}}^{-}$} & Jump? \\
\hline$\left[\mathbf{m}^{\mathbf{3}} / \mathbf{s}\right]$ & {$[\mathbf{m}]$} & {$[-]$} & {$[-]$} & {$[-]$} & {$[-]$} & \\
\hline 10.00 & 0.18 & 5.39 & 2.17 & 12.06 & 13.19 & $\mathrm{~F}_{\mathrm{o}}<F_{o}^{+}, F_{o}^{-}$ \\
\hline 50.00 & 0.31 & 9.92 & 2.17 & 7.00 & 8.75 & $\mathrm{~F}_{\mathrm{o}}>F_{o}^{+}, F_{o}^{-}$ \\
\hline 100.00 & 0.59 & 8.14 & 2.17 & 3.69 & 5.53 & $\mathrm{~F}_{\mathrm{o}}>F_{o}^{+}, F_{o}^{-}$ \\
\hline 150.00 & 0.88 & 6.66 & 2.17 & 2.47 & 4.25 & $\mathrm{~F}_{\mathrm{o}}>F_{o}^{+}, F_{o}^{-}$ \\
\hline 200.00 & 1.14 & 5.96 & 2.17 & 1.90 & 3.62 & $\mathrm{~F}_{\mathrm{o}}>F_{o}^{+}, F_{o}^{-}$ \\
\hline 250.00 & 1.40 & 5.24 & 2.17 & 1.55 & 3.21 & $\mathrm{~F}_{\mathrm{o}}>F_{o}^{+}, F_{o}^{-}$ \\
\hline 300.00 & 1.71 & 5.30 & 2.17 & 1.27 & 2.87 & $\mathrm{~F}_{\mathrm{o}}>F_{o}^{+}, F_{o}^{-}$ \\
\hline 350.00 & 1.85 & 5.15 & 2.17 & 1.17 & 2.75 & $\mathrm{~F}_{\mathrm{o}}>F_{o}^{+}, F_{o}^{-}$ \\
\hline 381.00 & 1.99 & 4.99 & 2.17 & 1.09 & 2.65 & $\mathrm{~F}_{\mathrm{o}}>F_{o}^{+}, F_{o}^{-}$ \\
\hline
\end{tabular}

9.1 Maximum dynamic pressure

Maximum dynamic pressures applicable to buckets are presented in the table below:

Table 3: Maximum dynamic pressure in the bucket

\begin{tabular}{|l|l|l|l|l|l|l|l|}
\hline Flow rate per passage & Radius & Angle of curvature & $\mathbf{F}_{\mathbf{0}}$ & $\mathbf{h}_{\mathbf{0}}$ & $\mathbf{H}_{\mathbf{P T}}$ & $\mathbf{H}_{\mathbf{P M}}$ & $\mathbf{X}_{\mathbf{P M}}$ \\
\hline$\left[\mathbf{m}^{\mathbf{3}} / \mathbf{s}\right]$ & {$[\mathbf{m}]$} & {$\left[{ }^{0}\right]$} & {$[-]$} & {$[\mathbf{m}]$} & {$\left[\mathbf{m H}_{\mathbf{2}} \mathbf{O}\right]$} & {$\left[\mathbf{m H}_{\mathbf{2}} \mathbf{O}\right]$} & {$[\mathbf{m}]$} \\
\hline 321 & 12 & 31 & 5.26 & 1.69 & 6.59 & 7.25 & 0.07 \\
\hline 381 & 12 & 31 & 4.99 & 1.67 & 5.79 & 6.45 & 0.07 \\
\hline
\end{tabular}

9.2 Zone of circulation and height of downstream waves

The level of water downstream has been determined with the help of the flood calibration curve in supposing at the same time the downstream regulation sluices used.

Table 4: Level of water and the height of the downstream waves

\begin{tabular}{|c|c|c|c|c|c|c|}
\hline $\begin{array}{ll}\begin{array}{l}Q_{\text {spillway }} \\
\text { passage }\end{array} & \text { per } \\
\end{array}$ & $\mathbf{Q}_{\text {sluice }}$ & $\mathbf{Q}_{\text {Global }}$ & $\mathbf{N}_{\text {downstream }}$ & $\mathbf{t}_{\mathrm{u}}$ & $\begin{array}{l}\text { Water height } \\
\text { downstream }\end{array}$ & $\begin{array}{l}\text { Height of waves } \\
\text { on impact } h_{s}\end{array}$ \\
\hline$\left[\mathrm{m}^{3} / \mathrm{s}\right]$ & {$\left[\mathrm{m}^{3} / \mathrm{s}\right]$} & {$\left[\mathrm{m}_{3} / \mathrm{s}\right]$} & [mCGL] & {$[\mathrm{m}]$} & {$[\mathrm{m}]$} & {$[\mathrm{m}]$} \\
\hline 321 & 885 & 2172 & 642.3 & 1.53 & 8.30 & 1.92 \\
\hline 381 & 897 & 2436 & 643.4 & 1.68 & 9.40 & 0.16 \\
\hline
\end{tabular}




\subsection{Trajectory of water layers}

Two calculations of the trajectory have been carried out for the each of the two layers of water in order to take into account the friction of air on water.

Table 5: Outlet angles of the inferior and superior layers

\begin{tabular}{|l|l|l|l|l|l|}
\hline Flow rate & $\mathbf{h}_{\mathbf{0}}$ & $\mathbf{V}_{\mathbf{o}}$ & $\mathbf{F}_{\mathbf{0}}$ & $\boldsymbol{\alpha}_{\mathbf{u}}$ & $\boldsymbol{\alpha}_{\mathbf{0}}$ \\
\hline$\left[\mathbf{m}^{\mathbf{3}} / \mathbf{s}\right]$ & {$[\mathbf{m}]$} & {$[\mathbf{m} / \mathbf{s}]$} & {$[-]$} & {$\left[{ }^{\circ}\right]$} & {$\left[^{0}\right]$} \\
\hline 321 & 1.69 & 21.72 & 5.26 & 25.08 & 23.34 \\
\hline 381 & 1.67 & 21.99 & 4.99 & 25.12 & 22.38 \\
\hline
\end{tabular}

Curves of maximum and minimum trajectories of water coming out of the bucket have been traced for a flow rate of $381 \mathrm{~m}^{3} / \mathrm{s}$ which corresponds to deca-millennial flood. The results presented in the table below take into account air to water friction (Figure 9).

Table 6: Spillway - distance between the point of impact of jet and the outlet point of bucket.

\begin{tabular}{|l|l|l|l|l|l|l|}
\hline $\begin{array}{l}\text { Return } \\
\text { Period }\end{array}$ & $\begin{array}{l}\text { Laminated flow } \\
\text { rate }\end{array}$ & $\begin{array}{l}\text { Global } \\
\text { flow rate }\end{array}$ & $\begin{array}{l}\text { Water level } \\
\text { downstream }\end{array}$ & $\mathbf{t}_{\mathbf{u}}$ & $\begin{array}{l}\text { Distance of impact } \\
\text { of inferior layer }\end{array}$ & $\begin{array}{l}\text { Distance of impact } \\
\text { of superior layer }\end{array}$ \\
\hline$[$ Yrs] & {$[\mathbf{m} / \mathbf{s}]$} & {$[\mathbf{m} / \mathbf{s}]$} & {$[\mathbf{m C G L}]$} & {$[\mathbf{m}]$} & {$[\mathbf{m}]$} & {$[\mathbf{m}]$} \\
\hline $10-10000$ & 321 & 2172 & 642.3 & 1.53 & 33 & 34 \\
\hline 10000 & 381 & 2436 & 643.4 & 1.68 & 31 & 32.5 \\
\hline
\end{tabular}

The distance of the jet coming out of the bucket is 30 to $35 \mathrm{~m}$ irrespective of the flood returns.

Figure 8: Trajectories of water layers for a deca-millennial flood

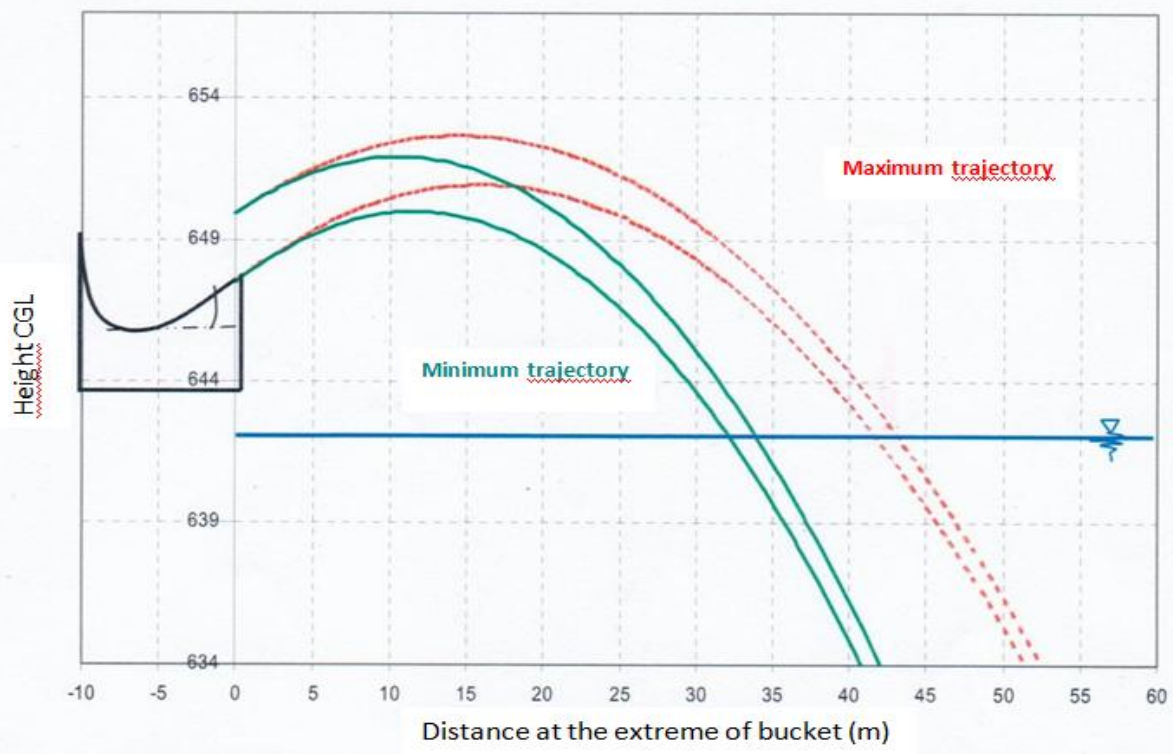

\subsection{Depth limit of erosion pits[1][6]}

At the level of the impact zone of the jet with the ground, for rare flood, the force of the jet is dissipated in a water mattress downstream creating an erosion pit. The depth of the limit of the scour is calculated using the empirical formula of Veronese after establishing stationary conditions:

with:

$$
\mathrm{t}+\mathrm{h}_{2}=1.9 \cdot \mathrm{H}^{0.225} \cdot \mathrm{q}^{0.54}
$$

$\mathrm{t}$ scour depth measured from the altitude of natural ground

$\mathrm{h}_{2} \quad$ depth of downstream water level

q specific flow rate

$\mathrm{H}$ height difference between normal reservoir water level and downstream water level

Table 7: Spillway - Scouring depth of the erosion pit

\begin{tabular}{|l|l|l|l|l|}
\hline Return period & Laminated flow rate & Upstream water level & Unit flow & Depth of scour \\
\hline$[\mathbf{Y r s}]$ & {$\left[\mathbf{m}_{3} / \mathbf{s}\right]$} & {$[\mathbf{m C G L}]$} & {$[\mathbf{m 3} / \mathbf{s . m}]$} & {$[\mathbf{m}]$} \\
\hline $10-10000$ & 321 & 672.70 & 36.70 & 27.10 \\
\hline 10000 & 381 & 673.55 & 43.50 & 29.70 \\
\hline
\end{tabular}


The scour is assumed to be centred on the zone of impact of the jet with the downstream water level. To determine the width of the erosion pit, a final slope of $1 / 1$ is adopted. The results show that the zone concerned by scouring of the downstream soil does not reach the foot of the downstream structure. The impact of the jet is far enough away from the bucket during flood evacuation.

\section{Conclusion}

Even when the worst of situations occur which is Probable Maximum Flood (PMF), there will be no scouring at the downstream of the dam. During flood the water level does not usually attain the exceptional level of 674.00 CGL. But during deca millennial flood or during PMF the water level can reach 675.45 which may result in the tilting of the fuse. However this is a very rare situation. Also there is no risk of cavitation during flood dissipation as can be seen from values obtained from the experiments and findings for the cavitation number $(\sigma)>2$. This then gives us the assurance that the spillway dissipation of energy during heavy floods can be guaranteed over the years.

\section{Reference}

[1]. Bollaert, E.F.R. A comprehensive model to evaluate scour formation in plunge pools. Int. WaterPower Dam Constr. 2004, 1, 94101

[2]. Chen, T.-C., and Yu, Y.-S. (1965). Pressure distribution on spillway flip buckets. J. Hydr. Div. ASCE 91(2), 51-63.

[3]. Genetti.A.J, U.S. Army Corps of Engineers Washington. DC ,(1990). Engineering and Design Hydraulic Design of Spillways

[4]. Juon, Roman and Hager,W. H.(2000). Flip Bucket Without and With Deflectors. Journal of Hydraulic Engineering, Vol. 126, No. 11,837-845 Doi: 10.1061/(ASCE)0733-9429(2000)126:11(837).

[5]. Mason, P. J. (1993). Practical guidelines for the design of flip bucket sand plunge pools. Water Power and Dam Constr., U.K., 45(9), 4045.

[6]. Mason, P.J.; Arumugam, K. Free jet scour below dams and flip buckets. J. Hydraul. Eng. ASCE1985, 11, 220-235.

[7]. Nor Azlina, A., et al. (2008).impact of take-off angle of bucket type energy dissipater on scour hole. American journal of Applied Sciences. 5(2): 117-121.

[8]. Steiner, R., et al. (2008). Deflector ski jump hydraulics. Journal of Hydraulic Engineering Vol. 134, No. 5, May 1, 2008. DOI:10.1061/(ASCE)0733- 9429(2008)134:5(562)

[9]. V. Heller, W. H. Hager, H. E. Minor, (F. ASCE); Ski Jump Hydraulics, Journal of Hydraulic Engineering, 2005. 